\title{
Determining Reservoir Type in Lower Cretaceous Terrigenic Sediments of Tersko-Sunzhensky Oil and Gas Bearing Region
}

\author{
Ezirbayev T.B. \\ Geophysics Laboratory \\ Complex R\&D Institute of the Russian Academy Sciences \\ Grozny State Oil Technical University \\ Grozny, Russia \\ timersno@mail.ru \\ Elzhayev A.S. \\ Department of Applied Geophysics and Geoinformatics \\ Grozny State Oil Technical University \\ Complex R\&D Institute of the Russian Academy Sciences \\ Grozny, Russia \\ aclambek.elzhaev@mail.ru
}

\begin{abstract}
Structural geological features of terrigenic AlbianAptian rocks of the Tersko-Sunzhensky oil and gas bearing region were studied, as well as their petrophysical and reservoir properties obtained from analysis of field geophysical tests and laboratory core analysis from previous years. Recently, reinterpretation of archive material for several wells and deposits has been done with modern automated systems and methods to refine the determination of the reservoir type in Albian-Aptian terrigenic deposits within the territory of interest.
\end{abstract} oil

Keywords - well logging, core, reservoir, method, interpretation,

\section{INTRODUCTION}

The first well logging operation in the wells of TerskoSunzhensky oil and gas bearing region drilled for Lower Cretaceous were conducted at the Karabulak-Achaluki deposit in 1955.

Later, in 1963, well surveys of Albian and Aptian rocks were also started at the Malgobek-Voznesenskoye deposit. In 1972, a complex of mandatory well surveys was approved that with time was extended with more contemporary methods of well logging. Thus, during the following years, acoustic survey and well survey with micro log tool were conducted in some individual wells. The obtained GIS data were largely of good quality and were used for qualitative and quantitative interpretation, however, one shall pay attention to a large error in recordings of micro logging charts $[2,3]$.

After a number of corrections and additions, the following complex of GIS was approved as mandatory for studies of Albian-Aptian deposits of the Tersko-Sunzhensky oil and gas bearing region (TSOGBR): Standard electrical logging, lateral sound logging, sidewall logging, induction logging, micro

\author{
Khasanov M.A. \\ Department of Applied Geophysics and Geoinformatics \\ Grozny State Oil Technical University \\ Complex R\&D Institute of the Russian Academy Sciences \\ Grozny, Russia \\ aclambek.elzhaev@mail.ru
}

\author{
Gatsayeva S.S.-A. \\ Department of Applied Geophysics and Geoinformatics \\ Grozny State Oil Technical University \\ Grozny, Russia \\ sveta_gacaeva@mail.ru
}

logging, acoustic logging, gamma ray logging, neutron gamma logging, well diameter logging.

However, even after a large scope of studies and GIS data analysis, the question of the reservoir type of the Albian-Aptian deposits in Lower Cretaceous has not been positively resolved.

\section{METHODS AND MATERIALS}

In 1965-1972, the type of reservoir in Karabulak-Achaluki and Malgobek-Voznesenskoye deposits was assumed as porous fractured. In 1978, from the results of analysis of development and assessment of residue oil stock at MalgobekVoznesenskoye deposit, the reservoir type was assumed as fractured. For Khayan-Kortskoye and Starogronzenskoye, deposits the prevailing type of reservoir was also determined as fractured [1].

One of the main issues in confirming the reservoir type in the Albian-Aptian rocks is determination of its intergrain saturation. Oil-saturation values of the studied rock matrices for Karabulak-Achaluki, Malgobek-Voznesenskoye and Starogroznenskoye were determined by laboratory analysis of core material.

The data from comparison of residual water saturation against permeability and porosity, plotted for main lithological groups of composing minerals: shales, siltstones and sandstones with breakdown for deposits of the TSOGBR form an indirect confirmation of the rock matrix saturation in addition to the laboratory data (Figure 1-3) [4].

Distribution of points in Figure 1 and their color show that, unlike shales and siltstones, sandstones may have the value of residual water saturation coefficient below $50 \%$. Some core samples have permeability on the order of $1-10 \mathrm{mD}$. 
$\mathrm{K}_{\mathrm{p}}$, unit fraction

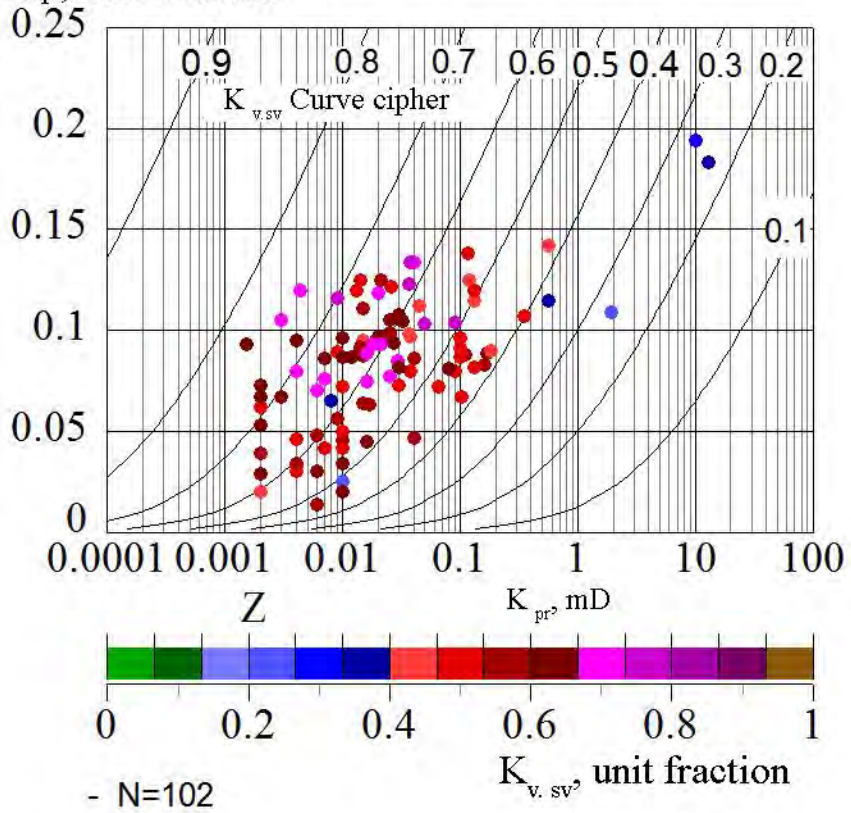

Fig. 1. A diagram of dependence for $K_{p r}=f\left(K_{p}, K_{v . s v}\right)$ Albian-Aptian deposits (a color of points in the diagram field correlates with the ratio of residual water).

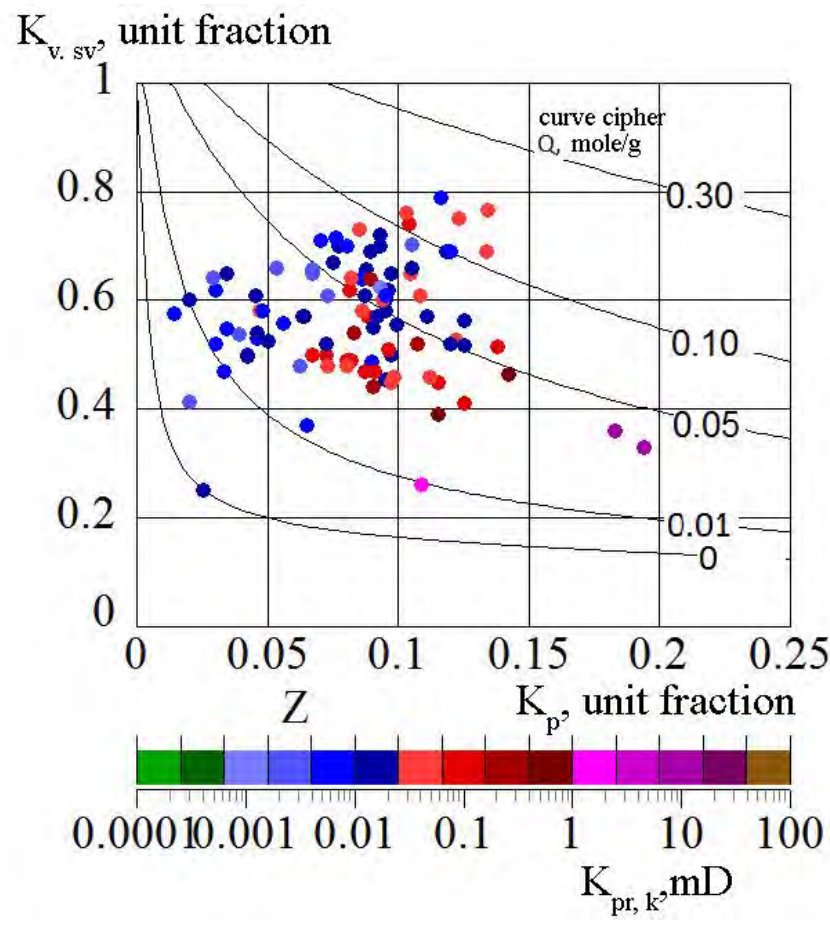

Fig. 2. Stoichiostic relation $K_{p r}=f\left(K_{p}, K_{p r}\right)$ from core data of TSOGBR deposits and $K_{v . s v}=f\left(K_{p}\right)$ lines calculated with the $K_{v . s v}$ model.

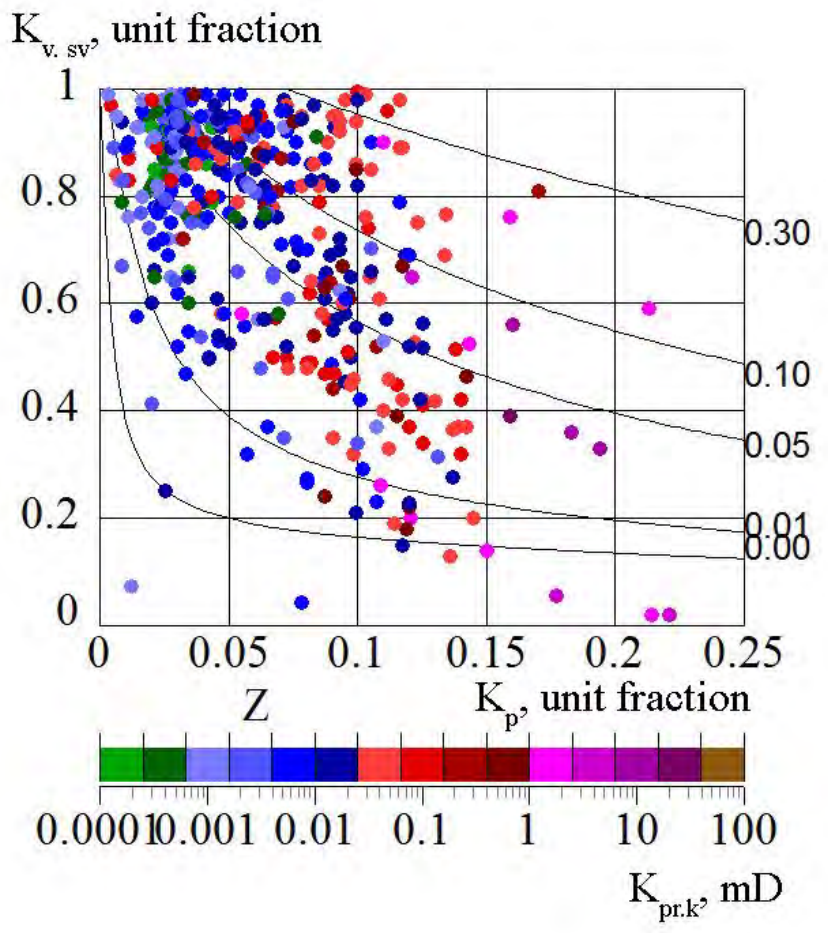

Fig. 3. Stoichiostic relation $K_{p r}=f\left(K_{p}, K_{p r}\right)$ from the results of GIS data interpretation for the TSOGBR deposits.

In the diagrams in Figures 2 and 3, there is a clear petrophysical regularity in changes of residual water volume in the rock as a function of their geological non-uniformity, reflected in changes of porosity and absolute permeability: with increased porosity and permeability, the share of residual water decreases.

As it is evident from comparing the diagrams in Figures 2 and 3 , the same relation for residual water is reconstructed from GIS data, as was previously obtained from core data.

Figure 4 shows a comparison of rock porosity with its content of siltstone and silt fractions as determined from core. A significant scattering of points in the diagrams is an evidence that the section of Albian-Aptian deposits is characterized with a significant variability of porosity, siltstone and shale volume. There is a trend for reduced porosity with increases in shale volume. However, with the same value of shale volume or siltstone content, the rock porosity may vary from minimum values of $K_{p \min }=2-3 \%$ to the maximum values whose level is independent of siltstone content, but depends of shale volume and decreases with its increase. 


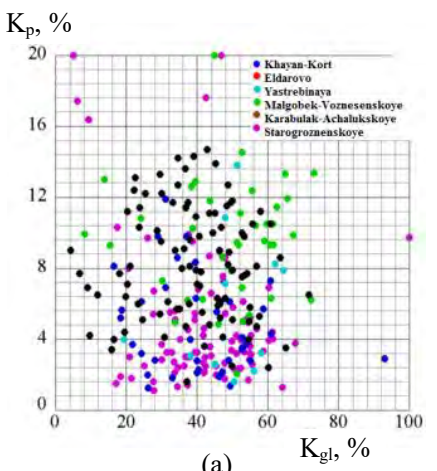

(a)

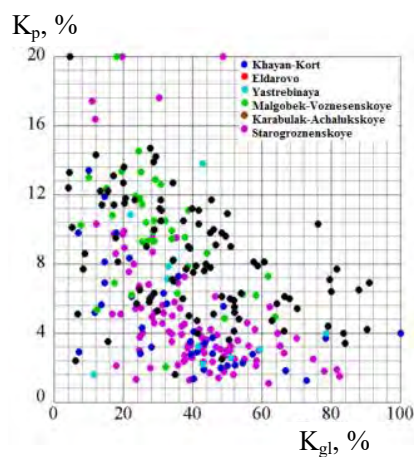

(b)

Fig. 4. Dependence of porosity on the share of siltstone (a) and shale (b) fraction.

Rock permeability in the vast majority of cases does not exceed $1 \mathrm{mD}$ and rarely reaches $20 \mathrm{mD}$. From the results of indicator mass exchange method (so-called tracer liquid method) it was established, that initial oil saturation of the productive deposit matrix of Albian-Aptian age varies from 60 to $74 \%$, and after complete flooding of the region may reach 8 $23 \%$.

From these data obtained by the methods stated above, some researchers, including the authors came to a conclusion that the oil deposits in terrigenic rock of Starogroznenskoye and Khayan-Kortskoye region pertain to the fractured cavernous reservoir type, while those in the Malgobek-Voznesenskoye and Karabulak-Achaluki pertain to the porous fractured type.

The results of petrographic and lithological study of rock give reasons to believe that at a depth of over $3000 \mathrm{~m}$, the main capacity of productive Aptian layers is represented by their primary intergrain porosity, together with leached porosity and fracture porosity, while oil may be extracted from the latter. Due to bad permeability of the matrix, oil from the studied reservoirs may be extracted only by capillary processes. On the other hand, importance of such matrix in the context of oil recovery is low, as the pores are filled with shale and regenerated quartz, thus impeding the capillary processes. As permeability of the matrix is low, microfractures serve as channels for fluid movement. On the basis of assessment of storage and filtration properties of Aptian rock, it may be concluded that productive Aptian layers pertain to the fractured porous type $[5,6]$.

The nature of saturation of the reservoir rock may also be determined from well survey geophysical data. It requires:

- calculating specific resistance of completely watersaturated reservoir for all the oil- and gas-bearing intervals (confirmed by reservoir testing) where acoustic logging gave quality curves;

- comparing the results with the values of specific resistance obtained in the laboratory.

Increase in the specific resistance may be explained by several causes: 1) influence of so-called cross cracks, 2) oil saturation of the rock, 3) joint influence of the first two factors $[7]$.

\section{RESULTS}

Speaking on the basis of the arguments given, the following model of the studied complex of rock may be assumed as a basis:

1. Albian-Aptian Lower Cretaceous rocks in the TSOGBR are largely composed of siltstone-shale deposits of quartz and feldspar composition. The shale component consists of hydrous mica with small admixtures of kaolinite and a very minor part of montmorillonite.

2. Porosity is intergrain, appearing due to compaction of sediments and solution cavities. There is fracturing in the rock. Fractures are of various length and form additional volume and permeability of the rock.

3. The reservoir type is complex porous fractured cavernous.

\section{CONCLUSION}

The peculiarities of structure of terrigenic rocks, their petrophysical characteristics and reservoir properties point to the fact that to identify and assess productive reservoirs and determine their type within the Lower Cretaceous productive deposits in the Chechen Republic, it is necessary to apply new methods of interpreting GIS data on the basis of modern geoinformational technologies and geophysical data processing and interpretation methods together with the laboratory analysis of cores and other available data. These schemes shall consider the features of the studied rocks noted above and shall be composed on the basis of using petrophysical models that take into consideration the influence that these properties exert over the indications of GIS-related methods.

High-level GIS data interpretation in the considered geological conditions is deemed fruitful only when using a methodology that provides reliable determination of geological properties of rock in the well section, development of volumetric and fluid models of the studied layer, identification of fractured zones.

Complex structural and mineral composition of the rocks and abundant presence of shaled siltstone material, presence of fractures in the rock massif define the features of petrophysical regularities established for these deposits. Taking these regularities into account is the basis for developing a GIS data interpreting methodology that will allow significantly increasing the reliability of filtration and capacity properties and oil saturation of Cretaceous deposits in the territory of Tersko-Sunzhensky oil and gas bearing region.

In the context of the above stated, the following may be considered the main tasks for development of reservoir type studies of the Albian-Aptian deposits of TSOGBR:

1. Justification of the petrophysical models for GIS data interpretaion for a three-component sandstone-siltstone-shale rock, which is, by the hypothesis, formed mainly by the siltstone fraction and has increased shale content and fracturing, with considerations for the modern level of development of terrigenic rock petrophysics [8]. 
2. Development of such a GIS data interpretation methodology that will allow determining sandstone, siltstone and shale components, carbonate cement, porosity, rate of bound and mobile water, mobile and residual oil, absolute permeability throughout the well sections in the Lower Cretaceous part of the TSOGBR deposits $[9,10]$.

3. Studies of the influence of fracturing when identifying and assessing the reservoir properties in the terrigenic complex of rock.

Testing the developed methodology of GIS data interpretation on actual well materials.

\section{Acknowledgement}

For this work, digital capture of analog data, processing and statistical analysis of the obtained information were conducted with the equipment of OOO GIFTS (Geoinformational Technologies and Systems) using the Gintel [7] system. The author acknowledges profound gratitude to his scientific consultant, Doctor of Technical Sciences, Professor Vitaliy Sergeyevich Afanasyev and General Director of OOO GIFTS (Geoinformational technologies and Systems), Candidate in Technical Sciences, Sergey Vitalyevich Afanasyev for their consultative and technical support.

\section{References}

[1] I.A. Kerimov, E.A. Abubakarova, S.V. Badaev, "Tridimensional analysis of the gravitational and magnetic fields of the Terek-Caspian trough", IOP Conference Series: Earth and Environmental Science, vol. 87, pp.1-6, 2017.

[2] I.A. Kerimov, M.Ja. Gajsumov, E.A. Abubakarova. Injenernyj vestnik Dona (Rus), vol. 4, part 1, pp. 1-9, 2012.

[3] Shnurman I.G, Studies of terrigenic reservoirs in the submountain region of Caucasus from the results of well surveys. Krasnodar: Prosveshcheniye-Yug, 2003.

[4] M.A. Hasanov, T.B. Ezirbaev, Petrophysical features of terrigenic Lower Cretaceous productive reservoirs of Tersko-Sunzhensky Oil and gas bearing region as a basis for GIS data interpretation, NTV Karotazhnik, Tver, vol. 8 (185), pp. 3-9, 2009.

[5] M.A Hasanov, B.L. Aleksandrov, A.S. Eljayev, T.B. Ezirbaev, S.S Gatsaeva, "Forecasting cracked collectors on anticlinal type structures at late stage of exploration in oil and gas area", IOP Conference Series: Earth and Environmental Science, vol. 87, pp.1-6, 2017.

[6] S.V. Afanasyev, Technology of a complex reinterpreting of geophysical well logging data when creating a 3D geological model of a deposit in prolonged development, Oil Industry, vol 2, pp.12-17, 2005.

[7] V.S. Afanasyev, S.V. Afanasyev, Gintel, a system of automated visual interpretation of log survey data. Description and User Manual, OOO "Geoinformational technologies and Systems", pp. 910, 2003.

[8] A.M. Gachaev. On fractal structure of oil and gas deposits. Engineering Annals of the Don, vol 1, pp. 1-10, 2011

[9] D.A. Kozhevnikov, Interpretation issues with NTZH, Information and Space, vol 1, pp. 29-4, 2005.

[10] M.V. Batashov, "Peculiarities of petrophysical features of Lower Cretaceous deposits of the Tersko-Sunzhensky oil and gas bearing region from geophysical data, Geology in the Developing World. Vol. 1, pp 134-136, 2013 